\title{
ARTICLE
}

\section{Study of the screening survey using an ambient dose equivalent rate survey meter in criticality accidents}

\author{
Katsuya Hoshi ${ }^{a^{*}}$, Norio Tsujimura ${ }^{\mathrm{a}}$, Tadayoshi Yoshida ${ }^{\mathrm{a}}$, Osamu Kurihara ${ }^{\mathrm{b}}$, Eunjoo Kim ${ }^{\mathrm{b}}$ and Kazuaki Yajima $^{\mathrm{b}}$ \\ ${ }^{a} J a p a n$ Atomic Energy Agency, 4-33 Muramatsu, Tokai-mura, Naka-gun, Ibaraki-ken, 319-1194, Japan; ${ }^{2}$ National Institutes for \\ Quantum and Radiological Science and Technology, 4-9-1 Anagawa, Inage-ku, Chiba-city, Chiba-ken,263-8555, Japan
}

\begin{abstract}
When a criticality accident occurs, a screening survey to triage high-dose radiation exposed persons is performed. We established a rapid method for the screening survey by measuring the gamma dose rate mainly from ${ }^{24} \mathrm{Na}$ in the victims' body with a conventional $\mathrm{NaI}(\mathrm{Tl})$ scintillation survey meter. In this study, a water-filled slab phantom containing $\mathrm{NaCl}$ was irradiated with neutrons from a ${ }^{252} \mathrm{Cf}$ neutron source. The radioactivity concentration of ${ }^{24} \mathrm{Na}$ produced in the phantom was determined by means of gamma-ray spectrometry and simulations using the Monte Carlo N-Particle Transport Code. The ambient dose equivalent rates at the phantom's outer surface were simulated by the Monte Carlo N-Particle Transport Code and were directly measured with a $\mathrm{NaI}(\mathrm{Tl})$ scintillation survey meter. From the experiments and calculations, we obtained the results that $1 \mathrm{~Gy}$ (neutron absorbed dose) corresponds to $18-76 \mu \mathrm{Sv} / \mathrm{h}$ (ambient dose equivalent rate) at the surface of the victim's body, which can be distinguished from normal background levels. Therefore, this method allows us to rapidly screen high-dose radiation-exposed victims.
\end{abstract}

Keywords: screening survey; criticality accidents; sodium activation; NaI(Tl) scintillation survey meter

\section{Introduction}

The first action taken immediately after a criticality accident is a screening measurement that distinguishes and sorts radiation-exposed persons in descending order by their severity of exposure. For this purpose direct surveys of neutron-induced radioactivity in a small piece of indium foil incorporated in personal dosemeters or ID badges have been widely used [1]. However, if such foil is unavailable for a victim, an alternative technique is to measure body sodium activation by placing a portable survey instrument of gamma rays against the victim's abdomen [2,3]. American National Standard ANSI/ANS- 8.23-2007 recommends the use of a conversion relationship stating that a neutron dose of 1 Gy will produce a net reading of $2.5 \mathrm{mR} / \mathrm{h}(\sim 25 \mu \mathrm{Sv} / \mathrm{h})$ immediately after exposure on a person weighing 200 pounds $(\sim 90 \mathrm{~kg})$ [4]. This relationship between the survey meter indication and the exposure dose was determined in the $1960 \mathrm{~s}$ from the results of an experiment on a saline-filled anthropomorphic phantom with a GM-based portable exposure rate meter after bombarding of accelerator-produced $2.1-\mathrm{MeV}$ neutrons [5]. This general relationship should be preferably translated and adjusted into a survey meter of modern design and also of wide domestic use in radiation protection community. This study describes a calibration

*Corresponding author. Email: hoshi.katsuya@jaea.go.jp experiment and calculation from which the response of a commonly-used $\mathrm{NaI}(\mathrm{Tl})$-based portable ambient dose equivalent rate survey meter is determined in terms of the neutron-induced activity $\left({ }^{24} \mathrm{Na}\right.$ and $\left.{ }^{38} \mathrm{Cl}\right)$ and the resultant neutron dose.

\section{Materials and methods}

\subsection{Experiment}

The main neutron-induced activities produced in a human body after neutron exposure are due to ${ }^{24} \mathrm{Na}$ (half-life: $15 \mathrm{~h}$ ) and ${ }^{38} \mathrm{Cl}$ (half-life: $37 \mathrm{~min}$ ), both of which emit high-energy gamma rays that are detectable outside the body. To simulate an activated human body, the irradiation experiments were performed at the Instrument Calibration Facility of the Nuclear Fuel Cycle Engineering Laboratories, Japan Atomic Energy Agency. A water-filled slab phantom (outer dimensions: $30 \times 30 \times 15 \mathrm{~cm}^{3}$, inner dimensions: $28 \times 28 \times 13.75$ $\mathrm{cm}^{3}$ ) containing an aqueous solution of $\mathrm{NaCl}$ was irradiated with neutrons from a ${ }^{252} \mathrm{Cf}$ neutron source. We filled the phantom with $1.011 \mathrm{~kg}$ of $\mathrm{NaCl}$ and 10,500 $\mathrm{cm}^{3}$ of distilled water. The amount of ${ }^{23} \mathrm{Na}$ within the slab phantom per mass was $35 \mathrm{~g}$ per $\mathrm{kg}$, which was approximately 25 times that of the reference man $(\sim 100$ $\mathrm{g}$ per $70 \mathrm{~kg}$ ) [2]. The separation distance from the neutron sources to the front face of the phantom was 75 $\mathrm{mm}$. The irradiation time was $180 \mathrm{~min}$. To reduce the 
influence of neutron room scattering for irradiation, the phantom was covered with a container constructed with thin cadmium plates. Figure 1 shows the experimental setup. The neutron emission rate was $1.19 \times 10^{8} \mathrm{n} / \mathrm{s}$ at the time of the experiment (December 11, 2015).

After completion of the neutron irradiation, the ambient dose equivalent rate at the center of the front surface of the phantom was measured with a $\mathrm{NaI}(\mathrm{Tl})$ scintillation survey meter (TCS-172B, Hitachi, Ltd.). This meter was selected because it is most ubiquitous, i.e., likely found in most nuclear facilities and has fully sensitivity to the low ambient dose equivalent rate. The TCS-172B employs a $\varphi 25.4 \times 25.4 \mathrm{~mm}^{2} \mathrm{NaI}(\mathrm{Tl})$ crystal with a energy compensation circuit, which adjusts the output of pulses from the crystal so that the height of the pulse is proportional to the dose. Thus, a rate of the biased pulses above a discrimination level directly indicates the dose rate. The output of the survey meter was connected to a data logger (NR-2000, KEYENCE) with a data-sampling interval of $30 \mathrm{~s}$ recorded over two days, a period of approximately three half-lives of ${ }^{24} \mathrm{Na}$. The concentration of ${ }^{24} \mathrm{Na}$ in the aqueous solution was measured by a high-purity germanium (HPGe) detector, and also was calculated by the mean of following section. A Princeton Gamma-Tech p-type HPGe detector system was used for radioactivity measurements. The detector model was an IGC-10200 with closed-end coaxial geometry. Commercial Amptek DPPMCA digital acquisition software (ver. 1.0.0.12) and FitzPeaks gamma analysis and calibration software (ver. 3.71) were used to acquire and analyze the pulse height spectra for the sample measurement, respectively. The measurement time was set at $250,000 \mathrm{sec}$ to gain good counting statistics in detecting the $1.37 \mathrm{MeV}$ peak from longer-lived ${ }^{24} \mathrm{Na}$. The peaks of shorter-lived ${ }^{38} \mathrm{Cl}$ were not analyzed because they were expected to be overwhelmed by the background pulse height spectrum accumulated over the long measurement time.

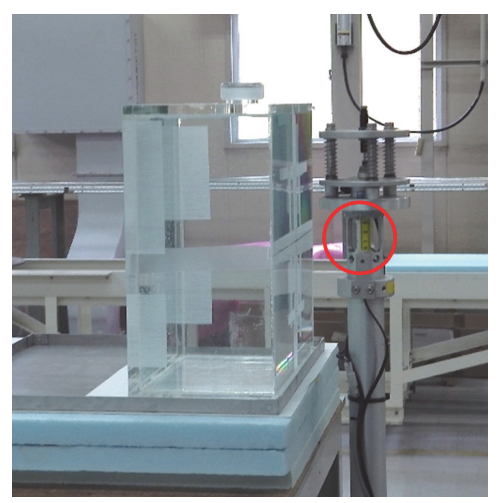

Figure 1. Photograph of the experimental setup (before covering the phantom with the cadmium container). The phantom was comprised of polymethyl-methacrylate (PMMA) walls (front wall $2.5 \mathrm{~mm}$ thick, other walls $10 \mathrm{~mm}$ thick). A circle in the photograph is the position of the neutron source.

\subsection{Calculation}

Two simulations were conducted to obtain the theoretical values of (1) the radioactivity concentrations of ${ }^{24} \mathrm{Na}$ and ${ }^{38} \mathrm{Cl}$ produced in the phantom and (2) the gamma dose equivalent rate at the surface of the phantom per unit ${ }^{24} \mathrm{Na}$ and ${ }^{38} \mathrm{Cl}$ radioactivity concentration. Monte Carlo N-Particle Transport Code (MCNP) was used to carry out these simulations [6].

The first simulation computed the amount of ${ }^{24} \mathrm{Na}$ and ${ }^{38} \mathrm{Cl}$ produced at the end of the neutron irradiation. The calculation model includes the neutron irradiation apparatus (the ${ }^{252} \mathrm{Cf}$ source, an aluminum transfer tube, and the electromagnet that holds the neutron source capsule) and the phantom filled with $\mathrm{NaCl}$ solution. Full details of the irradiation apparatus are described elsewhere [7]. The nuclear data library was from JENDL-3.2 [8], and the dosimetry data was from JENDL/D-99 [9]. The number of ${ }^{23} \mathrm{Na}(\mathrm{n}, \gamma)^{24} \mathrm{Na}$ and ${ }^{37} \mathrm{Cl}(\mathrm{n}, \gamma){ }^{38} \mathrm{Cl}$ reactions in the water was tallied using a track length estimator (F4 tally) with the multiplier of their microscopic cross sections. The output of the F4 tally denoted the number of reactions per unit water volume when one neutron is emitted from the source. The reaction rate was then obtained by multiplying the output by the volume of the water and the emission rate of the neutrons. The influence of neutron room scattering was disregarded in the simulation. In order to consider the compensation of the neutron-induced radioactivity lost during irradiation, not only a continuous irradiation but also an instantaneous irradiation was calculated.

The second simulation computed the gamma dose equivalent rate at the surface of the phantom per unit ${ }^{24} \mathrm{Na}$ and ${ }^{38} \mathrm{Cl}$ radioactivity concentration. In addition to the water-filled phantom, the same as used in the first part of the experiment, the water-filled BOttle Manikin ABsorption (BOMAB) phantom [10], comprising of nine cylinder bottles and representing a reference man's height of $170 \mathrm{~cm}$, was selected to account for the difference in the volume between the slab phantom and the actual human body. In the calculation, point isotropic gamma-ray sources of 1.37 and $2.75 \mathrm{MeV}$ from ${ }^{24} \mathrm{Na}$ and of 1.64 and $2.17 \mathrm{MeV}$ from ${ }^{38} \mathrm{Cl}$ were uniformly distributed throughout the water according to their respective emission abundances. The gamma-ray spectral fluence tallied by a point detector (F5 tally) were modified by the fluence-to-ambient dose equivalent conversion coefficients given in ICRP Publication 74 [11]. The F5 tally was placed $10 \mathrm{~mm}$ above the center of the front surface of the phantom, although for the BOMAB phantom it was placed $10 \mathrm{~mm}$ above the surface of the abdomen section, around the navel, $20 \mathrm{~cm}$ distant from the phantom's crotch. Calculations for the BOMAB phantom were also made for the following three positions: standing, sitting in a chair, and sitting in a chair and bending forward.

\section{Results and discussion}

Figure 2 shows the observed readings of the survey meter at various times after irradiation. The end of the 
irradiation was taken as $\mathrm{t}=0$. The observed readings appeared to be expressed in a double exponential curve, the time parameters of which were derived from the half-life of the short-lived ${ }^{38} \mathrm{Cl}$ and the long-lived ${ }^{24} \mathrm{Na}$. The initial reading, deduced by extrapolating the curve to $\mathrm{t}=0$ and subtracting the background radiations, was approximately $0.6 \mu \mathrm{Sv} / \mathrm{h}$.

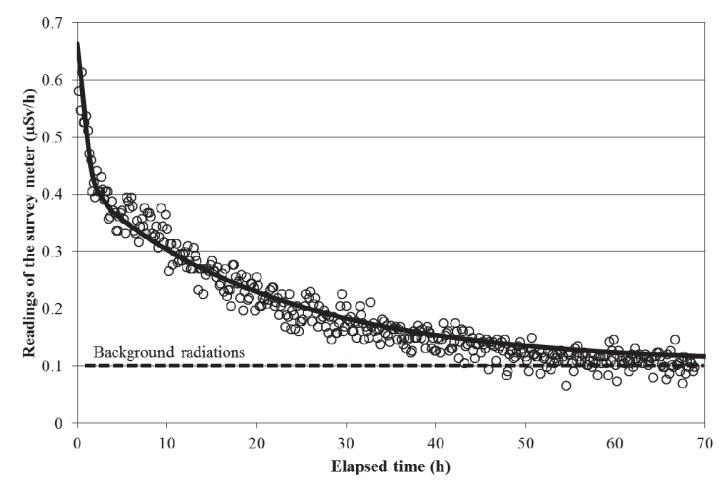

Figure 2. Readings of the survey meter at various times after irradiation on the water-filled slab phantom surface. The solid line is double exponential curve, the time parameters of which are derived from the half-life of ${ }^{38} \mathrm{Cl}$ and ${ }^{24} \mathrm{Na}$.

Table 1 summarizes measured and calculated radioactivity concentrations for ${ }^{24} \mathrm{Na}$ and ${ }^{38} \mathrm{Cl}$. Both results are decay-corrected to $\mathrm{t}=0$, i.e., the activities lost during the irradiation measurement are compensated. The calculated ${ }^{24} \mathrm{Na}$ concentration agreed with the measured concentration (within the measurement uncertainties). Moreover, we present the calculated ${ }^{24} \mathrm{Na}$ and ${ }^{38} \mathrm{Cl}$ radioactivity concentrations that would be produced from an instantaneous neutron irradiation of the same integrated neutron fluence as in the experiment. Immediately after the short-pulsed irradiation, encountered in most criticality accidents, the ratio of ${ }^{38} \mathrm{Cl}$ for ${ }^{24} \mathrm{Na}$ produced is expected to be approximately 4 in water-filled slab phantom.

Table 1 . Measured and calculated radioactivity concentrations for ${ }^{24} \mathrm{Na}$ and ${ }^{38} \mathrm{Cl}$ in the water-filled slab phantom.

\begin{tabular}{lccc}
\hline & $\begin{array}{c}\text { Irradiation/ } \\
\text { Cooling } \\
(\text { min. })\end{array}$ & $\begin{array}{c}{ }^{24} \mathrm{Na} \\
\left(\mathrm{Bq} / \mathrm{cm}^{3}\right)\end{array}$ & $\begin{array}{c}{ }^{38} \mathrm{Cl} \\
\left(\mathrm{Bq} / \mathrm{cm}^{3}\right)\end{array}$ \\
\hline $\mathrm{HPGe}$ & $180 / 10$ & $1.3( \pm 9.1 \%)$ & - \\
\hline \multirow{3}{*}{$\mathrm{MCNP}$} & $180 / 10$ & $1.3( \pm 0.3 \%)$ & $1.5( \pm 0.3 \%)$ \\
& $180 / 0$ & $1.3( \pm 0.3 \%)$ & $1.9( \pm 0.3 \%)$ \\
& $0 * / 0$ & $1.4( \pm 0.3 \%)$ & $6.4( \pm 0.3 \%)$ \\
\hline
\end{tabular}

*Instantaneous irradiation was assumed. However, integrated neutron fluence of instantaneous irradiation was the same as that of 180 -min irradiation.

Table 2 summarizes the calculated gamma-ray ambient dose equivalent rates at the surface of the phantoms that contain the same radioactivity concentrations of ${ }^{24} \mathrm{Na}$ and ${ }^{38} \mathrm{Cl}$ as shown in Table 1 . In the experiment, agreement was observed between the readings of the survey meter and the calculated dose rate. As for the instantaneous irradiation condition, the expected readings immediately after the irradiation are increased greatly because of the dose contribution from ${ }^{38} \mathrm{Cl}$. In addition, for the BOMAB phantom, $140 \%$, $200 \%$ and $220 \%$ higher readings are expected in the measurement positions for standing, sitting in a chair, and sitting in a chair and bending forward, respectively. This increase in the dose rate is due to the contribution of gamma rays emitted from the thighs.

Table 2. Ambient dose equivalent rates obtained from the calculations of the water-filled slab phantom and BOMAB phantom.

\begin{tabular}{|c|c|c|c|c|c|}
\hline \multirow{3}{*}{ Elapsed time (h) } & \multirow{3}{*}{$\begin{array}{c}\begin{array}{c}180-\text { min irradiation } \\
(\mu \mathrm{Sv} / \mathrm{h})\end{array} \\
\mathrm{Slab} \\
\end{array}$} & \multicolumn{4}{|c|}{$\begin{array}{c}\text { Instantaneous irradiation* } \\
(\mu \mathrm{Sv} / \mathrm{h})\end{array}$} \\
\hline & & \multirow[t]{2}{*}{ Slab } & \multicolumn{3}{|c|}{ BOMAB } \\
\hline & & & & Sitting $^{\mathrm{b}}$ & $\begin{array}{c}\text { Sitting and } \\
\text { bending forward }\end{array}$ \\
\hline 0 & 0.66 & 1.3 & 1.8 & 2.6 & 2.8 \\
\hline 0.25 & 0.60 & 1.1 & 1.5 & 2.2 & 2.4 \\
\hline 0.50 & 0.55 & 0.92 & 1.3 & 1.9 & 2.0 \\
\hline 0.75 & 0.52 & 0.80 & 1.1 & 1.6 & 1.7 \\
\hline 1 & 0.49 & 0.71 & 1.0 & 1.4 & 1.5 \\
\hline 2 & 0.42 & 0.51 & 0.72 & 1.0 & 1.1 \\
\hline 3 & 0.38 & 0.43 & 0.61 & 0.87 & 0.94 \\
\hline 4 & 0.36 & 0.39 & 0.55 & 0.79 & 0.85 \\
\hline 5 & 0.34 & 0.37 & 0.52 & 0.75 & 0.80 \\
\hline 10 & 0.27 & 0.29 & 0.41 & 0.59 & 0.63 \\
\hline 20 & 0.17 & 0.18 & 0.26 & 0.37 & 0.40 \\
\hline 30 & 0.11 & 0.11 & 0.16 & 0.23 & 0.25 \\
\hline 40 & 0.067 & 0.072 & 0.10 & 0.15 & 0.16 \\
\hline 50 & 0.042 & 0.045 & 0.064 & 0.092 & 0.10 \\
\hline
\end{tabular}

a. The size was based on ANSI/HPS N13.35-2009, Table 1.

b. The length of thighs when sitting was adjusted so that the volume of thigh when sitting was equal to that of thigh when standing.

c. The angle of bending forward was $30^{\circ}$.

*The integrated neutron fluence of the calculation was equal to that of 180 -min irradiation. 
According to Rapid Dose Assessment Program from Activated Sodium in Criticality Accidents (RADAPAS), 1 Gy (neutron absorbed dose including the contribution of capture gamma radiation in the victim's body) corresponds to $1.0 \times 10^{4}-4.2 \times 10^{4} \mathrm{~Bq} / \mathrm{g}$ (activity of ${ }^{24} \mathrm{Na}$ per unit mass of ${ }^{23} \mathrm{Na}$ ) [12]. This variation is due to the neutron spectral changes depending on types of critical assemblies and the shielding. Assuming that the mass concentration of the stable sodium isotope is $0.14 \%$ weight $\left(100 \mathrm{~g}\right.$ of ${ }^{23} \mathrm{Na}$ in a person weighing $70 \mathrm{~kg}$ ) and that specific gravity of body tissue is $1,14-59 \mathrm{~Bq} / \mathrm{cm}^{3}$ of ${ }^{24} \mathrm{Na}$ will be produced in a human body exposed by various neutron spectra in criticality accidents. From the results of Table 1 and Table 2, the ambient dose equivalent rate per $1 \mathrm{~Bq} / \mathrm{cm}^{3}$ of ${ }^{24} \mathrm{Na}$ was $0.93 \mu \mathrm{Sv} / \mathrm{h}$ under the condition of instantaneous irradiation. Thus, the readings of the survey meter under three conditions are expected to be follows: (1) $13-55 \mu \mathrm{Sv} / \mathrm{h}$, on the surface of the water-filled slab phantom, (2) $18-76 \mu \mathrm{Sv} / \mathrm{h}$, on the victim's abdomen when standing, and (3) 26-109 $\mu \mathrm{Sv} / \mathrm{h}$ on the victim's abdomen when sitting in a chair, (4) $28-118 \mu \mathrm{Sv} / \mathrm{h}$ on the victim's abdomen when sitting in a chair and bending forward. These results do not contradict the relation conversion stating in ANSI/ANS 8.23-2007.

\section{Conclusion}

In order to develop and establish a method that distinguishes and sorts radiation-exposed persons immediately after criticality accidents, we studied a method for the screening survey of victims by measuring the gamma dose rate from the neutron-induced radioactivity in the victim's body with conventional ambient dose equivalent rate survey meters. In this experiment, a water-filled slab phantom containing $\mathrm{NaCl}$ was exposed to neutrons from ${ }^{252} \mathrm{Cf}$ neutron source. The abundance of neutron-induced radioactivity in the phantom and the ambient dose equivalent at the surface of the phantom were simulated by MCNP. From the experiment and calculations, we obtained the result that 1 Gy (neutron absorbed dose) corresponded to an ambient dose equivalent rate of $13-55 \mu \mathrm{Sv} / \mathrm{h}$ at the surface of the phantom under pulse-irradiation conditions like in criticality accidents. These values included the contribution of the short half-life nuclide produced in the phantom. Considering the difference in volume between the phantom and the actual human body, the readings of the survey meter are expected to be $18-76 \mu \mathrm{Sv} / \mathrm{h}$ on the victim's abdomen when standing. Therefore, this method enables the high-dose radiation exposed victims to be rapidly screened using conventional $\mathrm{NaI}(\mathrm{Tl})$ scintillation survey meters.

\section{Acknowledgements}

This work was supported by a Labor Accident Disease and Clinical Research Grant.

\section{References}

[1] C. Takada, N. Tsujimura and S. Mikami, Recalibration of indium foil for personnel screening in criticality accidents, Radiat. Prot. Dosim. 144 (2011), pp. 575-579.

[2] IAEA, Dosimetry for criticality Accidents A Manual, Technical Report Series No. 211, (1982).

[3] K.G. Veinot, B.T. Gose, G. Davis and J.S. Bogard, Nucl. Tech. 168 (2009), pp. 17-20.

[4] ANSI, Nuclear Criticality Accident Emergency Planning and Response, ANSI/ANS-8.23-2007, (2007).

[5] R.H. Wilson, A method for immediate detection of high level neutron exposure by measurement of sodium-24 in humans, HW-73891Rev., (1962).

[6] J.F. Briesmeister (Ed), MCNP-A General Monte Carlo N-Particle Transport Code, Version 4C., Los Alamos National Laboratory, LA-13709-M, (2000).

[7] N. Tsujimura, T. Yoshida and T. Momose, Calculations of anisotropy factors for radionuclide neutron sources due to scattering from source encapsulation and support structures, Radiat. Prot. Dosim. 126 (2007), pp168-173.

[8] T. Nakagawa, K. Shibata, S. Chiba, T. Fukahori, Y. Nakajima, Y. Kikuchi, T. Kawano, Y. Kanda, T. Ohsawa, H. Matsunobu, M. Kawai, A. Zukeran, T. Watanabe, S. Igarashi, K. Kosako and T. Asami, Japanese evaluated nuclear data library, version 3 revision-2: JENDL-3.2, J. Nucl. Sci. Technol. 32 (1995), pp.1259-1271.

[9] K. Kobayashi, T. Iguchi, S. Iwasaki, T. Aoyama, S. Shimakawa, Y. Ikeda, N. Odano, K. Sakurai, K. Shibata, T. Nakagawa and M. Nakazawa, JENDL Dosimetry File 99 (JENDL/D-99), JAERI 1344, Japan Atomic Energy Research Institute, (2002).

[10]ANSI, Specifications for the Bottle Manikin Absorption Phantom, ANSI/HPS N13.35-2009, (2009).

[11]ICRP, Conversion Coefficients for Use in Radiological Protection against External Radiation, ICRP Publication 74. Ann. ICRP 26 (3-4)., International Commission on Radiological Protection, (1996).

[12]F. Takahashi, Program for Rapid Dose Assessment in Criticality Accident, RADAPAS, JAEA-Data/Code 2006-019, Japan Atomic Energy Research Institute, (2006). 